Check for updates

Cite this: RSC Adv., 2019, 9, 25429

\title{
Effect of ozone treatment on the phenylpropanoid biosynthesis of postharvest strawberries $\dagger$
}

\author{
Cunkun Chen, ${ }^{\text {ab }}$ Huijie Zhang, ${ }^{c}$ Chenghu Dong, ${ }^{d}$ Haipeng Ji, ${ }^{d}$ Xiaojun Zhang, ${ }^{\text {ab }}$ \\ $\mathrm{Li} \mathrm{Li,} \mathrm{(D)}{ }^{\mathrm{e}}$ Zhaojun Ban, ${ }^{f} \mathrm{Na}$ Zhang $^{\mathrm{d}}$ and Wentong Xue (D) *ab
}

\begin{abstract}
Ozone treatment at a suitable concentration can improve the antioxidant capacity of postharvest fruits. However, few studies have examined the antioxidant bioactive compounds in ozone-treated postharvest strawberries, especially in relation to proteomics. In this study, the total phenol content (TPC), total flavonoid content (TFC), and total anthocyanin content (TAC) were used as the main antioxidant compound indicators and unlabeled proteomics was used to study the metabolism of phenylpropanoids in postharvest strawberries (Jingtaoxiang) treated with different concentrations of ozone $(0,1,3$, and 5 $\mathrm{ppm}$ ) throughout the duration of storage. The results showed that the postharvest strawberries treated with 5 ppm ozone concentration exhibited improved accumulation of total phenols, flavonoids and anthocyanins in the antioxidant bioactive compounds, which was beneficial to the expression of phenylpropanoid metabolism-related proteins over the whole storage period compared with the other three groups. The results of proteomics were consistent with the changes in the key metabolites of phenylpropanoids, which indicated that ozone treatment at a suitable concentration aids the accumulation of TPC, TAC and TFC by promoting the key proteins associated with phenylpropanoid metabolism.
\end{abstract}

Received 26th May 2019

Accepted 2nd August 2019

DOI: $10.1039 /$ c9ra03988k

rsc.li/rsc-advances texture, softening rate, high breathing rate and vulnerability to fungal attack. ${ }^{4}$

Ozone is a strong oxidizing agent and is considered to have positive effects on the storage of strawberries; some studies showed that ozone treatment can effectively inhibit fungal attack on strawberries, ${ }^{5-7}$ remove residual pesticides, ${ }^{8}$ and extend the storage time of strawberries. ${ }^{9}$ Ozone water treatment at a concentration of $0.3 \mathrm{ppm}$ maintains the firmness, color and ascorbic acid content of the postharvest strawberries. ${ }^{10}$ However, Ana Allende et al. found that the phenolic content of the strawberries treated with $\mathrm{O}_{3}$ gas $\left(5000 \mathrm{mg} \mathrm{L}^{-1}\right)$ was significantly reduced due to the reduction of procyanidins, and the vitamin C content was lowest at the end of storage. ${ }^{11}$ However, our previous research found that a $5 \mathrm{ppm}$ ozone treatment can promote the synthesis of strawberry anthocyanins. ${ }^{12}$

Phenylpropanoid biosynthesis as a biological plant pathway for the synthesis of antioxidant substances, such as total flavonoid content (TFC), total anthocyanins content (TAC) and total phenolic content (TPC), has been reviewed extensively. ${ }^{13,14}$ Miao et al. found that the red and yellow films lead to the significant increase in the total anthocyanin content-related enzyme activity and the expressions of structural genes and transcription factor genes during the growth of strawberries. ${ }^{15}$ Also, 21 proteins and isoforms related to anthocyanin biosynthesis were investigated using quantitative proteomics at three ripening stages of two strawberry cultivars. ${ }^{16} \mathrm{Xu}$ et al. concluded that calcium may enhance the accumulation of anthocyanins 
and total phenols in fruits by increasing the expression of anthocyanin structural genes using RT-qPCR at the green, turning, and ripe stages. ${ }^{17}$ However, there are few proteomics and genomic studies on the phenylalanine-flavonoid metabolic pathway of postharvest strawberries and little research on the effects of ozone treatment on the phenylalanine metabolism of postharvest strawberries.

Therefore, the "Jingtaoxiang" strawberry was used as a test material, and four different concentrations of ozone gas $(0 \mathrm{mg}$ $\left.\mathrm{m}^{-3}, 1 \mathrm{ppm}, 3 \mathrm{ppm}, 5 \mathrm{ppm}\right)$ were used in this experiment to investigate the mechanism of phenylpropanoid metabolism in postharvest strawberries treated by ozone. The effects of different concentrations of ozone on the content of flavonoids, total phenols, and anthocyanins in strawberry fruits during storage were investigated, and label-free proteomics and qRTPCR techniques were used to detect the effects of ozone treatment on postharvest strawberries at 7 and 21 days to explore the metabolic pathway.

\section{Materials and methods}

\subsection{Plant materials and treatments}

Strawberries (Fragaria ananassa Duch. 'JingTaoXiang') were collected on February 15, 2018 in the modern agricultural science and technology innovation base (Wuqing District, Tianjin, China) and transported to the laboratory within $1 \mathrm{~h}$; next, strawberries of uniform size, with accordant maturity, and no pests, diseases, or mechanical damage were selected for the experiments. The fruit handling and sample preparation procedure was published in a previous work. ${ }^{12}$ Strawberries were randomly divided into four groups: three treatment groups and one control group. Every group was assigned 18 boxes and each box weighed approximately $300 \mathrm{~g}$. Each group was placed in the ozone treatment cabinet at $0,7,14$, and 21 days with different concentrations of ozone $(1,3$, and $5 \mathrm{ppm}$ ) for $10 \mathrm{~h}$ every 7 days using a precise ozone refrigerated fumigation device made in the National Engineering Research Center for Agricultural Products Preservation (Tianjin) ${ }^{\mathbf{1 2}}$ and transferred to $4{ }^{\circ} \mathrm{C}$ cold storage.

Three samples of each treatment group were taken at 7 days and 21 days for the analysis of proteins and six samples (five storage points) were taken for the determination of the index.

\subsection{TFC}

The extraction method of total phenols refers to the method reported by Cao and $\mathrm{Xu} .{ }^{18,19}$ After accurately weighing $1.0 \mathrm{~g}$ of strawberry fruit tissue, $5.0 \mathrm{~mL}$ of pre-cooled $95 \%$ ethanol (containing 3\% formic acid) was added, ground under ice bath conditions and transferred to a $15 \mathrm{~mL}$ sample vial. The sample was then mixed and sonicated for $5 \mathrm{~min}$, shaken for $30 \mathrm{~min}$, and centrifuged at $10000 \times g{ }^{\circ} \mathrm{C}$ for $15 \mathrm{~min}$; the supernatant was collected. The filter residue was secondarily extracted with $15.0 \mathrm{~mL}$ of $80 \%$ ethanol (containing $5 \%$ formic acid). After the same extraction process, the twice extracted supernatant was mixed, filtered and diluted up to $25 \mathrm{~mL}$ for the determination of total flavonoid content.
The total flavonoid content (TFC) was determined by the colorimetric method by Jia with slight modifications. ${ }^{20}$ We added $0.5 \mathrm{~mL}$ of the extract to $4.5 \mathrm{~mL}$ of distilled water; we immediately added $0.3 \mathrm{~mL}$ of $5 \%(\mathrm{w} / \mathrm{v}) \mathrm{NaNO}_{2}$ solution and then, we added $0.6 \mathrm{~mL}$ of $10 \%(\mathrm{w} / \mathrm{v}) \mathrm{AlCl}_{3}$ solution after $5 \mathrm{~min}$. After $6 \mathrm{~min}, 2.0 \mathrm{~mL}$ of $1 \mathrm{M} \mathrm{NaOH}$ solution was added, and the mixed reactants were made up to $10 \mathrm{~mL}$ with distilled water and thoroughly mixed. The absorbance was read at $510 \mathrm{~nm}$ using distilled water as a blank. The results were expressed as milligrams of catechin equivalent CE mg per $\mathrm{g}$ fresh weight (FW).

\subsection{TAC}

The analysis of anthocyanin content was performed using ultra performance liquid chromatography (UPLC), and the method has been described in our previous article. ${ }^{12}$ A sample of anthocyanin extract $(10 \mathrm{~mL}$; methanol : acetone : water : formic acid $=40: 40: 20: 0.1$ ) was added to $5.0 \mathrm{~g}$ strawberry, and the mixture was thoroughly ground and exposed to ultrasonic treatment $(35 \mathrm{kHz})$ for $10 \mathrm{~min}$ at $20{ }^{\circ} \mathrm{C}$. The mixture was centrifuged at $12000 \mathrm{rpm}$ at $4{ }^{\circ} \mathrm{C}$ for $20 \mathrm{~min}$. The supernatant was concentrated on a rotary evaporator at $40{ }^{\circ} \mathrm{C}$ and dissolved in $5.0 \mathrm{~mL}$ of a duplicate solution (water : ACN : formic acid = $93: 7: 2.5$ ). Finally, the sample was filtered through $0.22 \mu \mathrm{m}$ filters and injected.

The UPLC system consisted of a low temperature automatic injection, a photodiode array detector, and a chromatographic column (Waters ACQUITY UPLC BEH C18 column, $2.1 \times 50$ $\mathrm{mm}, 1.7 \mu \mathrm{m})$. The injection volume was $10 \mu \mathrm{L}$ and the flow rate was $0.4 \mathrm{~mL} \min ^{-1}$. Mobile phase A: $2.5 \mathrm{~mL}$ formic acid/100 mL water, mobile phase $\mathrm{B}$ : chromatographic grade acetonitrile (ACN). Gradient elution conditions: 0-5 min, 93-90\% A, 7-10\% B; 2 min, 90-80\% A, 10-20\% B; 12-14 min, 80-0\% A, 20-100\% B; 14-15 min, 0-93\% A, 100-7\% B; and 15-20 min, 93\% A, 7\% B. The detection wavelength was $500 \mathrm{~nm}$ and the scanning wavelength was $210-600 \mathrm{~nm}$. The column temperature was $30^{\circ} \mathrm{C}$ and the sample temperature was $20^{\circ} \mathrm{C}$. The content was expressed as $\mathrm{mg}$ P3G equivalent (C3GE)/100 $\mathrm{g}$ FW.

\section{$2.4 \quad$ TPC}

The extraction method of total phenolic content (TPC) was the same as the method of TFC. TPC was determined using the Slinkard's method. ${ }^{21}$ We added $1.0 \mathrm{~mL}$ of the Folin phenol reagent to $0.2 \mathrm{~mL}$ of the diluted solution and mixed at room temperature for $4 \mathrm{~min}$; then, we added $0.8 \mathrm{~mL} \mathrm{Na}_{2} \mathrm{CO}_{3}$ solution $(7.5 \%, w / v)$. After $1 \mathrm{~h}$ in the dark room, the absorbance was measured with a spectrophotometer at a wavelength of $765 \mathrm{~nm}$. The absorbance of the gradient concentration of gallic acid was determined under the same conditions to prepare a standard curve. The results are expressed as $\mathrm{mg}$ gallic acid equivalent GAE mg per $g$ fresh weight (FW).

\subsection{Proteomic analysis}

A detailed procedure of protein extraction, LC-MS/MS, protein identification and data validation and bioinformatics analysis is described in previous publications. ${ }^{12}$ The quality data of strawberry samples are shown in Table 1 . The digested peptides 
Table 1 Quality data of strawberry samples ${ }^{a}$

\begin{tabular}{llllllr}
\hline Sample & Weight $(\mathrm{g})$ & Optical density & $\begin{array}{l}\text { Protein concentration } \\
\left(\mu \mathrm{g} \mu \mathrm{L}^{-1}\right)\end{array}$ & Total volume $(\mu \mathrm{L})$ & Total protein $(\mu \mathrm{g})$ & Volume of electrophoresis $(\mu \mathrm{L})$ \\
\hline Blank 0 & 0.8 & 1.029 & 1.76 & 150 & 264 & 14.23 \\
Blank 7 & 0.8 & 1.058 & 1.96 & 150 & 294 & 12.75 \\
1 ppm 7 & 1.0 & 1.159 & 2.67 & 150 & 401 & 9.36 \\
3 ppm 7 & 0.8 & 1.023 & 1.71 & 150 & 415 & 14.61 \\
5 ppm 7 & 1.0 & 1.173 & 2.77 & 150 & 297 & 9.03 \\
Blank 21 & 0.8 & 1.061 & 1.98 & 150 & 301 & 12.62 \\
1 ppm 21 & 0.8 & 1.065 & 2.01 & 150 & 354 & 10.46 \\
3 ppm 21 & 0.8 & 1.115 & 2.36 & 150 & 411 & 9.12
\end{tabular}

${ }^{a}$ Here, the blank 0 is the initial time, and blank, 1 ppm, 3 ppm, 5 ppm 7/21 are the control, 1 ppm, 3 ppm, and 5 ppm treatment groups at day $7 / 21$, respectively.

were analysed on a Q-Extractive HF mass spectrometer (Thermo Scientific, Waltham, MA, USA) coupled with an Ultimate 3000 system (Thermo Scientific). The procedure of LC-MS/MS was the same as that reported by Chen and Cox et al. ${ }^{12,22,23}$ Tandem mass spectra were searched against Mascot 2.0 (Matrix Science, London, UK) using a UniProt sequence database. ${ }^{24} \mathrm{~A}$ fragment mass tolerance of $0.02 \mathrm{Da}$ and a peptide mass tolerance of $10 \mathrm{ppm}$ were used for both search engines. Raw spectrum data were processed using SEQUEST software to extract peak lists. The obtained peak lists were analyzed using the Proteome Discoverer (Thermo Scientific, version 1.4) against strawberry RNA-seq sequences combined with the sequences of common contaminants, such as human keratins. The false discovery rates (FDR) were set to 0.01 . The database we searched for was a transcriptome of the strawberry fruit (the experimental material) spliced by a UniGene protein sequence translated into a protein database consisting all the plant protein sequences blast on the protein database and UniProt comment information.

Using the protein extracted from the strawberry harvested before storage as a denominator, the ratio of the normalised spectral counts from the late storage of the strawberry proteome was compared to assess differential adjustments of proteins in response to treatment. The steps of normalized spectral abundance factor (NSAF) normalization ${ }^{25}$ are as follows: the first step is to calculate the sum of all proteins in a single sample; the second step, i.e., dividing the SUM value by the largest SUM value in several samples yields a decimal number between 0 and 1 (two reserved bits), which is the coefficient of variation; the third step is getting the original protein signal value, which is the deviation coefficient of each protein sample.

\subsection{RNA extraction and quantitative reverse transcription PCR (qRT-PCR) analysis}

Based on the differential expressions of protein-related phenylpropanoid synthesis, 21 key proteins in the $5 \mathrm{ppm}$ ozone treatment group and blank group were selected for expression verification using qRT-PCR. The detailed method is described in a previous article ${ }^{12}$ and special primers were designed using Primer 3.0 software shown in ESI Table S1. $\dagger$

\subsection{Statistical analysis}

Data statistics and analysis were performed using the same method as a previous article. ${ }^{12}$ Data were analyzed using analyses of variance (ANOVA) with the SPSS 22 software. The least significant difference (LSD) was calculated to determine significant differences at the 5\% level. Bioinformatics analysis was carried out to categorise proteins based on biological processes, cellular components, and molecular functions using annotations in the Protein Analysis Through Evolutionary Relationships (PANTHER) database v 6.1 (http:// www.pantherdb.org), which is in compliance with gene ontology standards. Signalling pathway analysis was performed with the tools in the Kyoto Encyclopedia of Genes and Genome database (http:// www.genome.jp/kegg/pathway.html). Clusters of orthologous groups category assignment was performed using the local alignment tool BLASTP with ane-value cutoff of $<104$. Hierarchical clustering analysis was performed with Mev 4.9 software. All the results are expressed as the mean \pm S.E.M of three replicates $(n=3)$. Using a 1.25 -fold change (FC) and $p$-values $<0.05$ as the variance for an upor down-shift in abundance, FC $\geq 1.25$ and $p<0.05$ were considered to reflect upregulation, while $\mathrm{FC} \leq 0.75$ and $p<0.05$ were considered to reflect downregulation.

\section{Results}

\section{$3.1 \quad$ TFC}

Flavonoids are a class of secondary metabolites that are abundant in plants and have a strong scavenging effect on free radicals. As shown in Fig. 1, TFC of the 5 ppm treatment group accumulated in the first 21 days of storage, reaching the maximum on the 21st day. However, it tended to decrease in the $1 \mathrm{ppm}$ and blank treatment groups. The total flavonoid content was the highest in the $5 \mathrm{ppm}$ group, followed by the blank and $1 \mathrm{ppm}$ groups, and finally the 3 ppm group on day 7; however, TFC in the 3 ppm group exceeded that in the $1 \mathrm{ppm}$ group on the 21st day of storage. The TFC of the $5 \mathrm{ppm}$ group was $0.29 \mathrm{CE} \mathrm{mg}$ per $\mathrm{g}$ FW on the 7th day, which increased by $12.39 \%$ compared with that for the initial time. However, the TFC in the $1 \mathrm{ppm}$ and $3 \mathrm{ppm}$ groups decreased during the first 7 days by $6.65 \%$ and $30.41 \%$, respectively. On the 21 st day, the total flavonoid content of the $5 \mathrm{ppm}$ treatment group was 0.31 CE mg per g FW and that for the second blank group was 0.24 


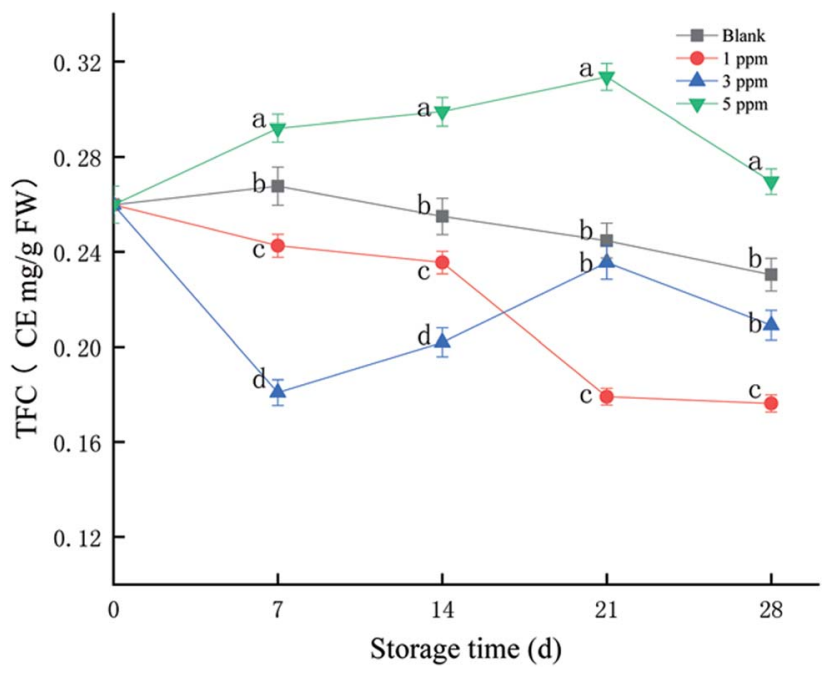

Fig. 1 Effect of different concentrations of ozone treatment on TFC during strawberry storage, where the letters $a, b, c$, and $d$ represent significant differences in the same day between the different treatment groups $(P<0.05)$.

CE mg per $\mathrm{g}$ FW; moreover, the value for the 3 ppm treatment group was $0.23 \mathrm{CE} \mathrm{mg}$ per $\mathrm{g}$ FW, and the lowest value was found for the 1 ppm treatment group: $0.17 \mathrm{CE}$ mg per $\mathrm{g}$ FW. In addition, the TFC content in the $5 \mathrm{ppm}$ treatment group was significantly higher than those in the $1 \mathrm{ppm}$ and $3 \mathrm{ppm}$ treatment groups and blank group during the whole storage time $(P<0.05)$.

\subsection{TAC}

As shown in Fig. 2, TAC in the 5 ppm ozone treatment group continued to increase during the first 21 days of storage, reaching a maximum on the 21st day. The TAC values for the $3 \mathrm{ppm}$ treatment group and blank group did not change significantly throughout the storage period; the maximum values were 13.5 and

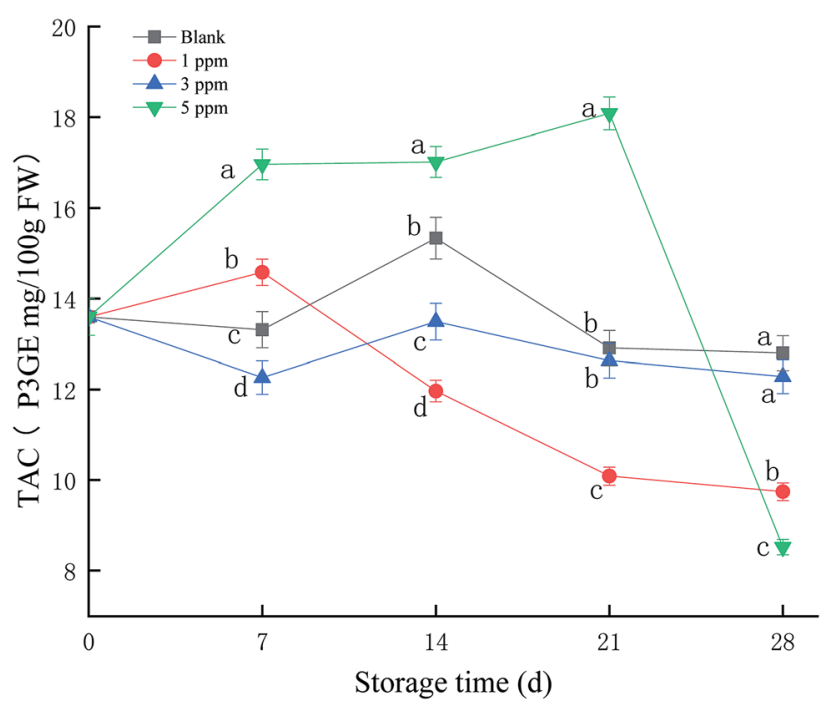

Fig. 2 Effect of different concentrations of ozone treatment on TAC during strawberry storage, where the letters $a, b, c$, and d represent significant differences in the same day between the different treatment groups $(P<0.05)$.
15.3 P3GE mg/100 $\mathrm{g}$ FW, respectively, on the 14th day of storage. However, the TAC value for the $1 \mathrm{ppm}$ treatment group increased slightly on the 7th day of storage and then continued to decrease, with a peak for 14.5 P3GE mg/100 $\mathrm{g} \mathrm{FW}$ on the 7th day. Overall, the 5 ppm treatment group promoted the synthesis of anthocyanins in strawberries during storage, especially on the 21st day of storage, and the anthocyanin content was significantly higher than that in the blank group and the $1 \mathrm{ppm}$ and $3 \mathrm{ppm}$ ozone treatment groups $(P<0.05)$.

\subsection{TPC}

Different fruits have different characteristic phenols, and the main polyphenol in strawberries is $p$-hydroxybenzoic acid. Phenolic compounds can provide electrons or hydrogen atoms, participate in the scavenging of free radicals and prevent the accumulation of free radicals. As shown in Fig. 3, the total phenolic content (TPC) of the $5 \mathrm{ppm}$ treatment group increased from $1.17 \mathrm{GAE} \mathrm{mg}$ per $\mathrm{g} \mathrm{FW}$ at the beginning of storage to $1.75 \mathrm{GAE} \mathrm{mg}$ per $\mathrm{g} \mathrm{FW}$ at the end of storage, an increase of $49.57 \%$, which was the highest compared with those of the other treatment groups $(P<0.05)$ during the storage time. TPC in the $3 \mathrm{ppm}$ treatment group was reduced on day 7 and then rapidly accumulated and exceeded the ck and $1 \mathrm{ppm}$ treatment groups on day 21 and 28 . The $3 \mathrm{ppm}$ and 5 ppm treatment groups were able to prevent decrease in the total phenolic content in strawberries at the end of storage, and 5 ppm ozone treatment significantly promoted the formation of phenolic compounds.

\subsection{Protein identification and quantification}

The results of the proteins associated with PAL metabolism between different treatment groups at different storage times are shown in Fig. 4 and 5 and ESI Table S2. $\dagger$

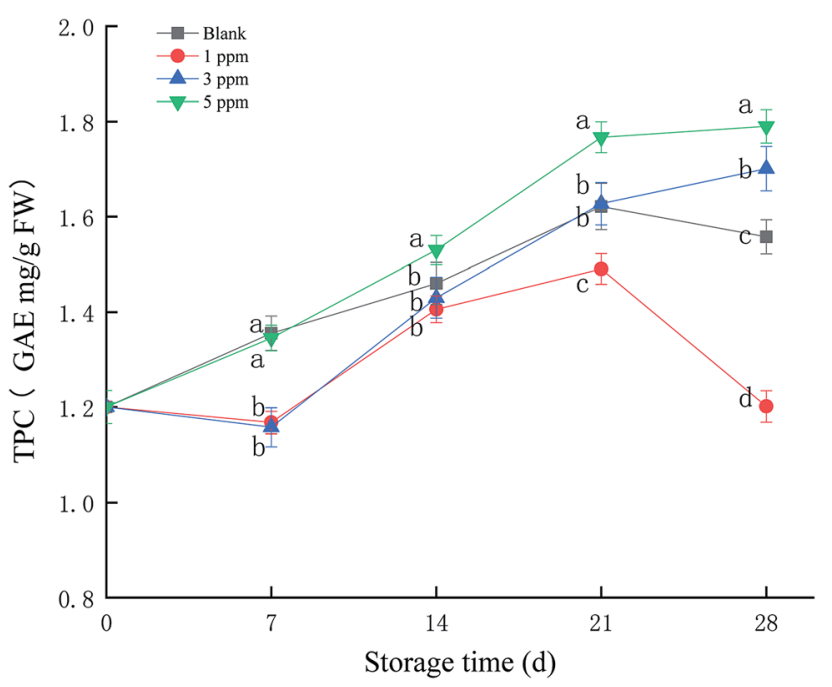

Fig. 3 Effect of different concentrations of ozone treatment on TPC during strawberry storage, where the letters $a, b, c$, and d represent significant differences on the same day between the different treatment groups $(P<0.05)$. 
As shown in ESI Table S2, $\uparrow 21$ key proteins associated with PAL biosynthesis were investigated in all the detected proteins. The number of proteins detected as dihydroflavonol reductase (DFR) was 4, and the same number was detected for anthocyanidin synthase (ANS). Also, 6 proteins were related to the synthesis of chalcone and chalcone isomerase, and the numbers of the proteins associated with 4-coumarate, phenylalanine ammonia-lyase, UDP-glucose flavonoid 3-O-glucosyltransferase (3GT), flavanone 3-hydroxylase (F3H), and cinnamate were $2,1,1,2$, and 1 , respectively.

The difference in the protein expressions associated with phenylpropanoid metabolism in the different treatment groups on the seventh day of storage was evident from Fig. 4. Compared with the initial value, the expressions of 4 proteins were upregulated and those of 5 proteins were down-regulated in the control group on the seventh day of storage; the amount of 3 proteins in the 5 ppm ozone treatment group increased, and the expression of 2 proteins decreased; the content of the 2 proteins increased, and the expressions of 9 proteins decreased in the $1 \mathrm{ppm}$ ozone treatment group; the expressions of 14 proteins were significantly down-regulated in the $3 \mathrm{ppm}$ ozone treatment group. The protein content associated with phenylpropanoid biosynthesis did not increase significantly in each treatment group on the 7th day, but a significant downward trend in the $1 \mathrm{ppm}$ ozone treatment group and the $3 \mathrm{ppm}$ ozone treatment group was observed.

After storage for 21 days, the clustering heat map of the protein expression levels of each treatment group was obtained, as shown in Fig. 5. There was a significant downward trend in the control group and the $1 \mathrm{ppm}$ ozone treatment

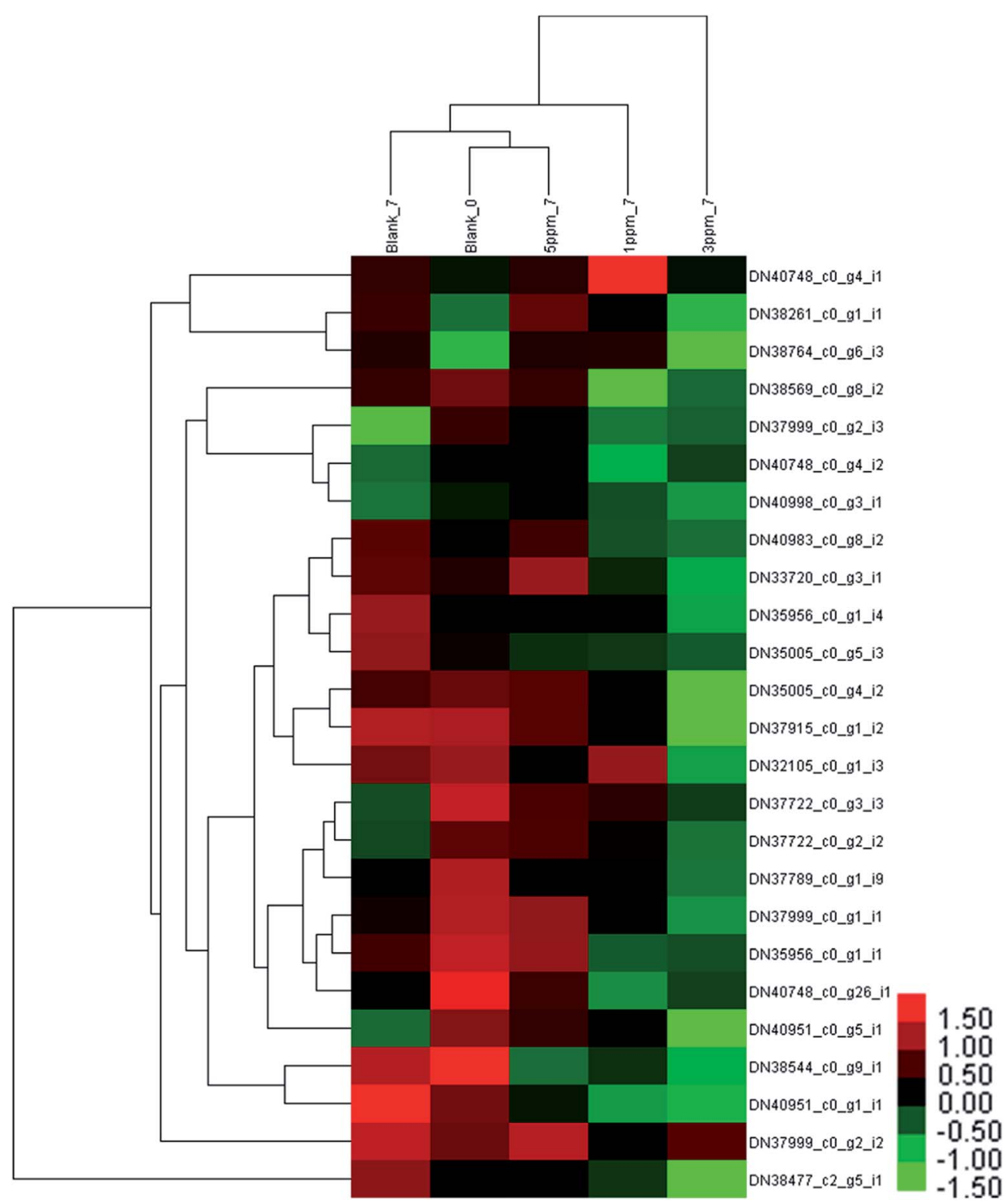

Fig. 4 Hierarchical clustering analysis of 25 proteins identified in the strawberries at the initial time and after 7 days of storage in 4 treatments. Blank_0 is the initial time, Blank_7, 1 ppm_7, 3 ppm_7 and 5 ppm_7 are the blank, 1 ppm, 3 ppm and 5 ppm at day 7, respectively. 


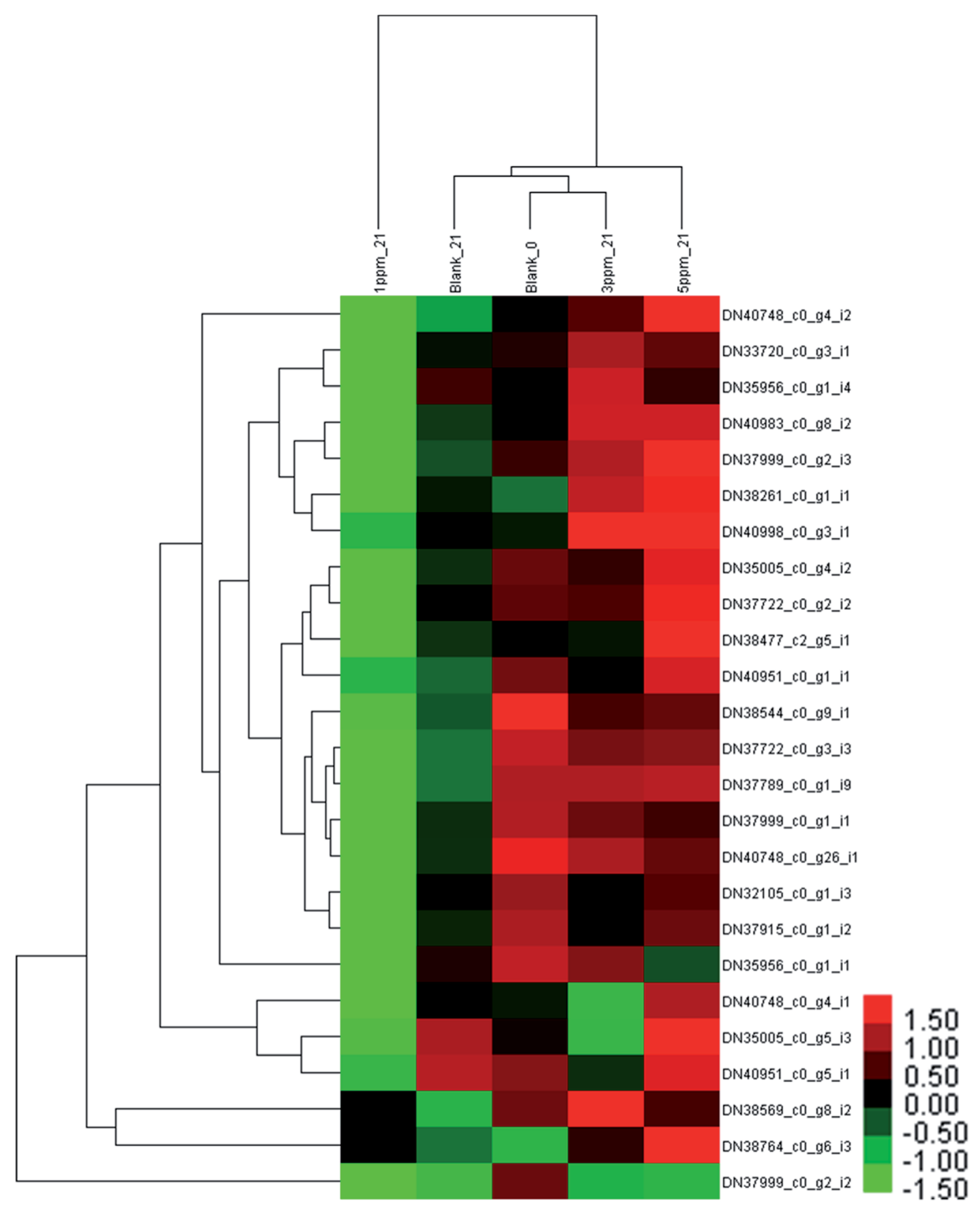

Fig. 5 Hierarchical clustering analysis of 25 proteins identified in the strawberry after 21 days of storage in four treatments compared with the initial time. Blank_21, 1 ppm_21, 3 ppm_21 and 5 ppm_21 are the blank, 1 ppm, 3 ppm and 5 ppm at day 21.

group, and the expression levels of 10 proteins in the control group were significantly down-regulated compared with those of 20 in the 1 ppm treatment group. However, the content of 9 proteins in the 5 ppm treatment group significantly increased, and the expression of only one protein was down-regulated compared with the initial value.

It can be seen from Fig. 6 that the trend of 21 proteins in the control group is unchanged first and then is up-regulated. However, the trend of these proteins in the $1 \mathrm{ppm}$ treatment group was always decreasing, which was first reduced and then increased in the $3 \mathrm{ppm}$ treatment group. There was no significant change in the protein expression in the $5 \mathrm{ppm}$ treatment group on day 7 , but it increased significantly on day 21.
Overall, only the 5 ppm ozone treatment group remained at a high level in terms of protein expression throughout the 21 days of storage.

The proteins associated with phenylpropanoid metabolism were detected at the transcriptional level on day 7 and 14 of storage using qRT-PCR. As is shown in Fig. 6, most of the results are consistent with those of the label-free test except DN35005_c0_g5_i3, DN37789_c0_g1_i9, DN38764_c0_g6_i3, and DN40983_c0_g8_i2 on day 7 and DN35956_c0_g1_i4, DN35005_c0_g5_i3, DN37999_c0_g2_i2, DN35956_c0_g1_i1, and DN37915_c0_g1_i2 on day 21. DN37915_c0_g1_i2 did not change in the qRT-PCR results but was up-regulated in the label-free results, while other inconsistent protein results were highly expressed at the RNA levels (Fig. 7). 


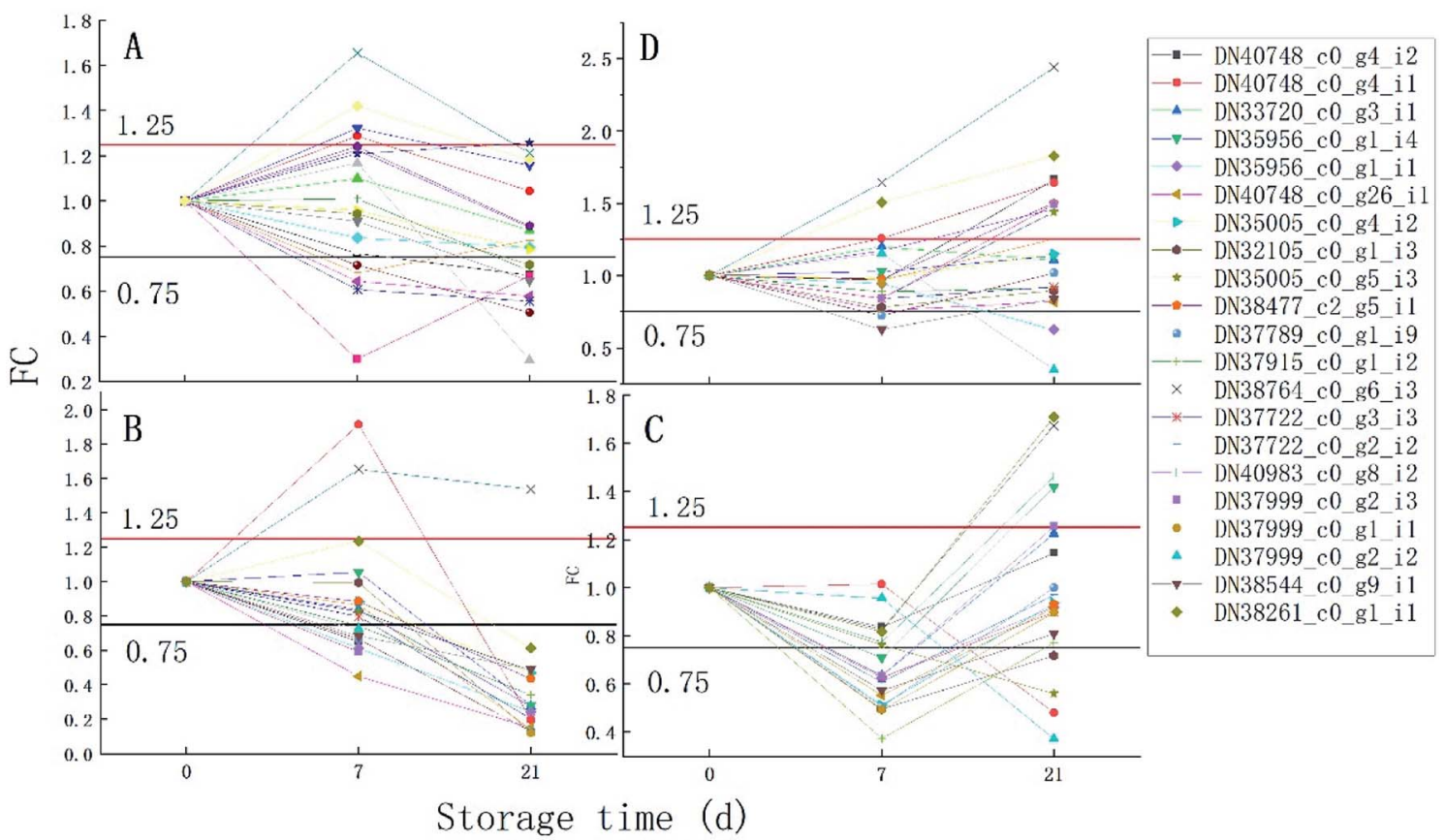

Fig. 6 The trend of 21 proteins in different treatment groups throughout the storage time. (A) is the blank group; (B) is the 1 ppm ozone treatment group; (C) is the 3 ppm ozone treatment group; $(D)$ is the 5 ppm ozone treatment group.

\section{Discussion}

Phenolic substances, flavonoids, and anthocyanins are considered to be the primary non-enzymatic antioxidants in plants. ${ }^{26,27}$ Many studies have found that ozone can induce the secondary metabolites of phenylpropanoid metabolism in plants. Francine et al. found that the leaves of $P$. edulis are resistant to ozone by accumulating flavonoids. ${ }^{28}$ Additionally, the accumulation of total phenolics and total flavonoids in postharvest grapes and Ganoderma lucidum is promoted by ozone treatment. ${ }^{29,30}$ Piyatida et al. found that B. cereus enhances the resistance to $\mathrm{O}_{3}$ by increasing flavonoids in plant tissues. ${ }^{31}$ Mohammad et al. found that the total phenolic and flavonoid contents of pineapples and bananas increased significantly when exposed to ozone for 20

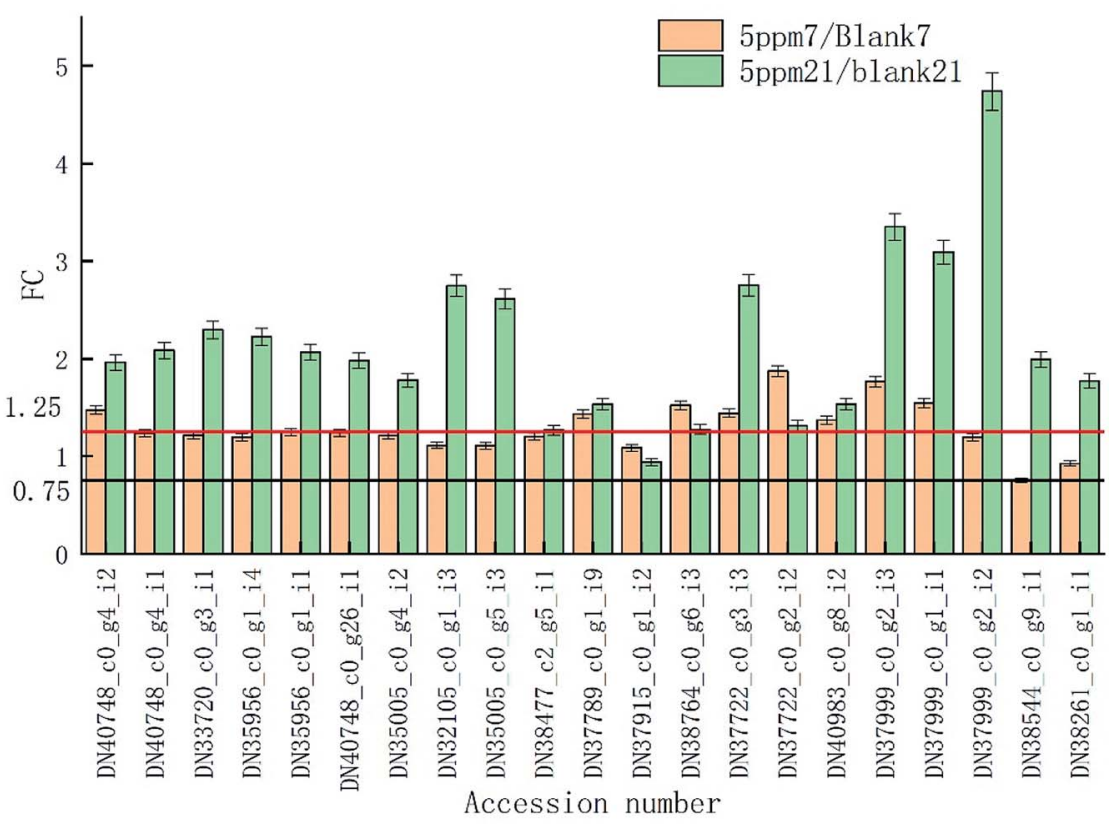

Fig. 7 Expression profiles of the 20 genes via qRT-PCR. Note: 5 ppm 7/Blank_7 means the expression of 5 ppm ozone treatment group/blank group at day 7; 5 ppm 21/Blank_21 means the expression of 5 ppm ozone treatment group/blank group at day 21. 
minutes. ${ }^{32}$ A majority of the flavonoids in the pericarp of hot peppers increased upon treatment with ozone for 3 hours. $^{7}$ In this study, TFC, TAC and TPC in the 5 ppm ozone treatment group were higher than those of the other three treatment groups throughout the duration of storage except for the sudden decrease in anthocyanins on the 28th day. The transfer of anthocyanins in fruits and the strong oxidative properties of ozone may be responsible for the rapid decline at the end of storage in the 5 ppm treatment group; ${ }^{33,34}$ also, high concentrations of ozone treatment can lead to the production of more intermediate free radicals, which can promote the nucleophilic or electrophilic substitution reaction of the ortho and para positions of the aromatic compound with high electron density, resulting in decrease in the anthocyanin content. ${ }^{35}$ TPC and TFC were maintained at a high level in the $5 \mathrm{ppm}$ treatment group at the end of storage, which may be due to the oxidative metabolism of anthocyanins to phenolic acids and flavonoids. ${ }^{36-38}$ However, the $3 \mathrm{ppm}$ treatment group and the $1 \mathrm{ppm}$ treatment group did not have an obvious preservation effect compared with the control group; TPC, TAC and TFC in the 3 ppm and 1 ppm ozone treatment groups were significantly lower than that in the control group at day 7 and 21, respectively, which may be because different ozone concentrations induce different metabolic pathways. ${ }^{39}$

Transcriptomics and proteomics can explain the mechanism for the changes in total phenolics, total flavonoids and anthocyanins. ${ }^{14}$ Li et al. discovered the potential target proteins of gene modification in the breeding program by investigating the protein expression and metabolite profiles of phenolic biosynthesis during the ripening of blueberry fruits. ${ }^{40}$ Fitzgerald et al. found that the transcription of a large number of phenylpropyl pathway genes in Arabidopsis thaliana L. is stimulated by ozone, which may be an important mechanism for some plants to resist ozone stress. ${ }^{41}$ The induction of defense-related secondary metabolites and the concomitant increase in the transcript levels of PAL and CHS genes by semi-quantitative RTPCR gene expression analysis indicated that Liriodendron tulipifera utilized this pathway to partially offset the oxidative damage of ozone. ${ }^{42}$ The important roles of CHI and CHS, two key flavonoid synthetases, in the phenylpropanoid metabolic pathway have been demonstrated by a large number of studies. ${ }^{43,44}$ Zhang et al. found that the overexpression of the CHS gene can increase the anthocyanin content in leaves and isoflavonoid biosynthesis in soybeans was stimulated by the expression of CHS8. ${ }^{45,46}$ There is a positive correlation between the gene expression of $\mathrm{CHI}$ and the content of total flavonoids during grape ripening. ${ }^{47}$ An increase in the $\mathrm{CHI}$ transcript level and $\mathrm{CHI}$ activity increases the accumulation of flavonoids. ${ }^{48}$ Phenylalanine ammonia lyase (PAL), cinnamic acid 4-hydroxylase $(\mathrm{C} 4 \mathrm{H})$ and 4-coumaric acid:CoA ligase (4CL) participate in the general phenylpropane pathway. ${ }^{49,50}$ Dihydroflavonol 4reductase (DFR), a protein closely related to the anthocyanin content and strawberry coloration, ${ }^{51-53}$ can catalyze the formation of strawberry leucoanthocyanidin by dihydroflavonols, ${ }^{54,55}$ and the ANS enzyme catalyzes the production of colored anthocyanins from strawberry proanthocyanidins (especially pelargonidin); ${ }^{56}$ the $\mathrm{F} 3 \mathrm{H}$ enzyme hydroxylates flavanones form 3-hydroxy flavonol, a common precursor of anthocyanins, flavanols, and proanthocyanidins. ${ }^{57}$

The phenylpropanoid metabolism of ozone-treated strawberries has not been explored at the transcriptomics and proteomics levels. In this study, the expression levels of PAL (DN38544_c0_g9_i1), 4CL (DN37789_c0_g1_i9 and DN37915_c0_g1_i2), C4H (DN38261_c0_g1_i1) and the three CHI (DN33720_c0_g3_i1, DN35956_c0_g1_i4 and DN35956_c0_g1_i1) proteins were lower than those of the control group on the 7th day of storage; the abundances of ANS (DN40983_c0_g8_i2, DN37999_c0_g1_i1) and all 4 proteins identified as DFR (DN35005_c0_g4_i2, DN32105_c0_g1_i3, DN35005_c0_g5_i3 and DN38477_c2_g5_i1) were also less in the $3 \mathrm{ppm}$ treatment group compared with that for the other three groups. This indicated that the phenylpropanoid metabolic pathway was inhibited in the pre-storage phase of the 3 ppm treatment group, resulting in low TPC, TAC, and TFC.

The reason for higher TAC in the $1 \mathrm{ppm}$ treatment group and the $5 \mathrm{ppm}$ treatment group than that in the CK and $3 \mathrm{ppm}$ treatment groups may be because CHS DN40748_c0_g4_i1 in the 1 ppm treatment group, CHS (DN40748_c0_g4_i2) in the 5 ppm treatment group, and F3H (DN37722_c0_g3_i3 and DN37722_c0_g2_i2) in the two treatment groups were higher than those in the control group and the $3 \mathrm{ppm}$ treatment group.

On the 21st day of storage, TPC, TAC and TFC in the $1 \mathrm{ppm}$ treatment group were significantly lower than those in the other three treatment groups, which was consistent with the results of proteomics except for DN38764_c0_g6_i3 and DN38544_c0_g9_i1. The expressions of most proteins in the $3 \mathrm{ppm}$ treatment group and the $5 \mathrm{ppm}$ treatment group were higher than that in the control group. However, TAC and TFC in the $3 \mathrm{ppm}$ treatment group were still lower than those in the control group, which may be because very little precursor substances accumulated in the early stage.

Interestingly, TFC and TAC of strawberries in the $5 \mathrm{ppm}$ treatment group were significantly higher than those in the other three groups on the 7th and 21st day of storage, but the number and type of higher abundance proteins in the $5 \mathrm{ppm}$ treatment group were different compared to those of the other three treatment groups. This indicated that the effect of ozone on the phenylalanine metabolic pathway of postharvest strawberries is a complex regulation process, and the change in ozone concentration has different stimulating effects on the key genes related to phenylpropanoid metabolism in postharvest strawberries. In addition, $0.3 \mathrm{ppm}$ ozone water and $5 \mathrm{ppm}$ ozone gas could promote the accumulation of TPC, but the ozone gas concentration at $5000 \mathrm{mg} \mathrm{L}^{-1}$ reduced the phenolic contents and procyanidins; this may be observed because different ozone forms have different suitable concentrations for strawberry fresh-keeping, and a very high ozone concentration may directly oxidize the antioxidants of the postharvest strawberries. ${ }^{36,58}$ These results indicated that it is necessary to explore the appropriate concentration of ozone for the preservation of different fruits and vegetables, which was emphasized in the review by Glowacz et al. ${ }^{\mathbf{5 9 , 6 0}}$

In general, the production of total phenol, total flavonoids and total anthocyanins in postharvest strawberry 
phenylpropanoid metabolites was significantly promoted in the $5 \mathrm{ppm}$ ozone treatment group compared with that in the other three treatment groups, and the conclusions of proteomics were also consistent with these results; this indicated that a suitable concentration of ozone produces a higher level of antioxidant secondary metabolites by inducing the expression of key proteins in the metabolic pathway of phenylpropanoidanthocyanin.

\section{Conflicts of interest}

The authors declare there is no competing financial interest.

\section{Acknowledgements}

This work was supported by National Natural Science Foundation of China Youth Science Fund Project (31501547); 13th Five Key Research and Development of China (2016YFD0400903-05, 2018YFF0213605-2); the Innovation Team of the Tianjin Forestry \& Pomology Research System (ITTFPRS2018009); Tianjin Science and Technology Plan (17YFYZCG00010, 16ZXZYNC00070); Tianjin Natural Science Foundation Youth Project (16JCQNJC14800); Tianjin Agricultural Science and Technology Achievements Transformation and Promotion Project (201701100, 201602090); Tianjin Academy of Agricultural Sciences Dean's Fund $(17014,17012)$.

\section{References}

1 M. Glowacz, R. Colgan and D. Rees, J. Sci. Food Agric., 2015, 95(4), 662-671.

2 Y. Jiawei, L. Zisheng, B. Zhaojun, L. Hongyan, L. Dong and Y. Dongmei, Postharvest Biol. Technol., 2019, 147, 29-38.

3 F. Giampieri, J. Alvarez-Suarez, M. Gasparrini, T. Y. ForbesHernandez, S. Afrin, S. Bompadre, et al., Food Chem. Toxicol., 2016, 94(8), 128-137.

4 I. Lara, P. García and M. Vendrell, Sci. Hortic., 2006, 109(1), 48-53.

5 M. S. Aday, M. B. Büyükcan, R. Temizkan and C. Caner, Ozone: Sci. Eng., 2014, 36(1), 43-56.

6 Z. Hongyin, M. Longchuan, J. Song, D. Ying and Z. Xiaodong, Trans. Chin. Soc. Agric. Eng., 2009, 25(5), 258-263.

7 E. M. C. Alexandre, D. M. Santos-Pedro, T. T. S. BrandãO and C. L. M. Silva, J. Food Eng., 2011, 105(2), 277-282.

8 H. Ikeura, F. Kobayashi and M. Tamaki, J. Hazard. Mater., 2011, 186(1), 956-959.

9 M. S. Aday and C. Caner, LWT-Food Sci. Technol., 2014, 57(1), 344-351.

10 A. Emc, B. Trs and S. Clm, J. Food Eng., 2012, 108(3), 417-426. 11 A. Allende, M. Alicia, B. Begoña, T. Francisco and M. I. Gil, Postharvest Biol. Technol., 2007, 46(3), 201-211.

12 C. Chen, X. Zhang, H. Zhang, Z. Ban, L. Li, C. Dong, et al., RSC Adv., 2019, 9, 676-689.

13 A. C. Allan, R. P. Hellens and W. A. Laing, Trends Plant Sci., 2008, 13(3), 99-102.

14 T. Vogt, Phenylpropanoid biosynthesis, Mol. Plant, 2010, 3(1), 2-20.
15 L. Miao, Y. Zhang, X. Yang, J. Xiao, H. Zhang, Z. Zhang, et al., Food Chem., 2016, 207(15), 93-100.

16 J. Song, L. Du, L. Li, W. Kalt, L. C. Palmer, S. Fillmore, et al., J. Proteomics, 2015, 122, 1-10.

17 W. Xu, H. Peng, T. Yang, B. Whitaker, L. Huang, J. Sun, et al., Plant Physiol. Biochem., 2014, 82, 289-298.

18 J. Zhishen, T. Mengcheng and W. Jianming, Food Chem., 1999, 64(4), 555-559.

19 F. Xu, L. Shi, W. Chen, S. Cao, X. Su and Z. Yang, Sci. Hortic., 2014, 175, 181-186.

20 S. Cao, Z. Hu, Y. Zheng, Z. Yang and B. Lu, Food Chem., 2011, 125(1), 145-149.

21 K. Slinkard and V. L. Singleton, Am. J. Enol. Vitic., 1977, 28(1), 49-55.

22 J. Cox, N. Neuhauser, A. Michalski, R. A. Scheltema, J. V. Olsen and M. Mann, J. Proteome Res., 2011, 10(4), 1794-1805.

23 J. Cox and M. Mann, Nat. Biotechnol., 2008, 26(12), 1367.

24 K. Eitner, U. Koch, T. Gaweda and J. Marciniak, Bioinformatics, 2010, 26(23), 2933-2935.

25 M. Q. Dong, J. D. Venable, N. Au, T. Xu, S. K. Park and D. Cociorva, Science, 2007, 317(5838), 660-663.

26 F. Brahmi, B. Mechri, S. Dabbou, M. Dhibi and M. Hammami, Ind. Crops Prod., 2012, 38, 146-152.

27 K. E. Olagaray and B. J. Bradford, Anim. Feed Sci. Technol., 2019, 251(5), 21-36.

28 F. F. Fernandes, M. P. Esposito, M. R. G. da Silva Engela, P. Cardoso-Gustavson, C. M. Furlanand, Y. Hoshika, et al., Sci. Total Environ., 2019, 656, 1091-1101.

29 M. Margherita, P. Milena, F. Roberto, Z. Luigi, S. Marco and M. Fabio, Food Res. Int., 2018, 112(10), 369-377.

30 S. Sudheer, W. K. Yeoh and S. Manickam, Postharvest Biol. Technol., 2016, 117, 81-88.

31 P. Pheomphun, C. Treesubsuntorn, P. Jitareerat and P. Thiravetyan, Ecotoxicol. Environ. Saf., 2019, 171(4), 805812.

32 M. Alothman, B. Kaur, A. Fazilah, R. Bhat and A. A. Karim, Innovative Food Sci. Emerging Technol., 2010, 11(4), 666-671.

33 M. Sachadyn-Król, M. Materska, B. Chilczuk, M. Karaś, A. Jakubczyk, I. Peruckaa and I. Jackowska, Food Chem., 2016, 211(11), 59-67.

34 S. R. Segade, M. A. Paissoni, S. Giacosa, A. B. Bautista-Ortín, E. Gómez-Plaza, V. Gerbi and L. Rolle, Food Chem., 2019, 271, 673-684.

35 R. Bossuyt, Milchwissenschaft, 1978, 33, 11-13.

36 B. K. Tiwari, C. P. O'Donnell, A. Patras, N. Brunton and P. J. Cullen, Food Chem., 2009, 113(4), 1119-1126.

37 M. Özkan, Food Chem., 2002, 78(4), 499-504.

38 G. Hrazdina and A. J. Franzese, Phytochemistry, 1974, 13(1), 231-234.

39 R. L. Heath, Environ. Pollut., 2008, 155, 453-463.

40 X. Li, J. Liang, X. Pan, L. Yang and W. Guo, Food Chem., 2019, 290(8), 216-228.

41 F. L. Booker, K. O. Burkey and A. M. Jones, Plant, Cell Environ., 2012, 35(8), 1456-1466. 
42 E. Pellegrini, A. Campanella, L. Cotrozzi, M. Tonelli, C. Nali and G. Lorenzini, Environ. Sci. Pollut. Res., 2017, 25(3), 81488160.

43 Y. Wang, J. Li and R. Xia, Sci. Hortic., 2010, 125(2), 110-116. 44 Y. Wang, Y. Dou, R. Wang, X. Guan, Z. Hu and J. Zheng, Gene, 2017, 635(7), 16-23.

45 X. H. Zhang, X. T. Zheng, B. Y. Sun, C. L. Peng and W. S. Chow, Environ. Exp. Bot., 2018, 154, 33-44.

46 J. Yi, M. R. Derynck, X. Li, P. Telmer, M. Frédéric and S. Dhaubhadel, Plant J., 2010, 62(7), 1019-1034.

47 W. Wang, H. L. Wang, S. B. Wan, J. H. Zhang, P. Zhang, J. C. Zhan and W. D. Huang, Biol. Plant., 2012, 56(3), 545550.

48 H. C. Zhang, J. M. Liu, H. Y. Lu and S. L. Gao, Plant Cell Rep., 2009, 28(8), 1205-1213.

49 R. Zhai, Z. Wang, S. Zhang, G. Meng, L. Song, Z. Wang, P. Li, F. Ma and L. Xu, J. Exp. Bot., 2016, 67(5), 1275-1284.

50 C. Camila, D. Thomas, C. Alvaro, K. Sebastian, S. Ronan, L. Andrea, S. Dirk, F. R. Alisdair, W. Lothar and H. A. Matthew, Plant J., 2011, 67(5), 869-884.

51 Y. Chu, J. Pan, A. Wu, R. Cai and H. Chen, Sci. Hortic., 2014, 165, 398-403.
52 C. D. Viljoen, M. C. Snyman and J. J. Spies, S. Afr. J. Bot., 2013, 87, 18-21.

53 P. Petit, T. Granier, B. Langlois d'Estaintot, C. Manigand, K. Bathany, J. M. Schmitter, et al., J. Mol. Biol., 2007, 368(5), 1345-1357.

54 F. Henryk, H. Heidi, T. Dieter, R. Klaus, H. Magda-Viola, S. Iris, G. Christian, S. Karl and F. C. Thilo, Plant Physiol. Biochem., 2011, 51, 18-25.

55 D. K. Owens, K. C. Crosby, J. Runac, B. A. Howard and B. S. J. Winkel, Plant Physiol. Biochem., 2008, 46(10), 833-843.

56 S. Lunkenbein, M. Bellido, A. Aharoni, E. M. J. Salentijn, R. Kaldenhoff, H. A. Coiner, M. O. Juan and S. Wilfried, Plant Physiol., 2006, 140(3), 1047-1058.

57 Y. Han, K. Huang, Y. Liu, T. Jiao, G. Ma, Y. Qian, P. Wang, X. Dai, L. Gao and T. Xia, Gene, 2017, 8, 300.

58 R. Criegee, Angew. Chem., Int. Ed. Engl., 1975, 14(11), 745752.

59 M. Glowacz and D. Rees, J. Sci. Food Agric., 2016, 96(14), 4637-4643.

60 M. Glowacz, R. Colgan and D. Rees, J. Sci. Food Agric., 2015, 95(4), 662-671. 